\title{
Evaluation of a Vibration Source Detection Scheme
}

\author{
by
}

\author{
J. A. Jendrzejczyk, M. W. Wambsganss, and R. K. Smith \\ Materials and Components Technology Division \\ Argonne National Laboratory
}

\section{Introduction}

When the Advanced Photon Source (APS) facility is commissioned, there will be many potential sources of local ground motion excitation (near-field sources). Some of these may be of sufficient amplitude and at a specific frequency so $a j$ to be detrimental to the stability of the storage ring beaniline. A sampling of possible sources is as follows: 2500-hp chillers in the utility building; six coolingtower fans that are powered by 75 -hp electric motors; various water circulation pumps; power supplies, controllers, and transformers; and air-handling units and associated fans. To detect equipment that causes excessive ground excitation at a site as large as the APS, it will be necessary to have a validated source detection scheme.

When performing low-amplitude vibration testing in and around Building 335 of Argonne National Laboratory (ANL), we observed a cyclic $8-\mathrm{Hz}$ vibration. The cyclic nature of the signal is apparent in Fig. 1, which represents data measured on the floor at the main level of Building 335 on March 31, 1992. A simple vibration source location scheme, based on triangulation, was evaluated as a means to locate the source of the $8-\mathrm{Hz}$ vibration and is the subject of this tecinical note.

\section{Objective}

To use the 8- $\mathrm{Hz}$ vibration component inherent in the measurements of floor motion in, and ground motion in the vicinity of, Building 335 as the basis for evaluating a vibration source identification methodology.

\section{MASTER}




\section{Technical Approach}

A foundation or basemat that is oscillating on the surface of the earth will generate a wave field in the ground. The wave field generated in this manner is discussed in some detail by Richart et al. [1] and is summarized here. The energy coupled into the ground is transmitted away from the source by a combination of compression (P), shear (S), and Rayleigh (R) waves. The body waves ( $P$ and $S$ ) propagate radially outward along a hemispherical wave front, whereas the surface wave $(R)$ propagates along a cylindrical wave front. The energy density (or displacement amplitude) decreases with distance from the source in so-called geometrical damping. Cil the surface, body waves decrease in amplitude in proportion to $1 / \mathrm{r}^{2}$, whereas Rayleigh waves decrease as $1 / \sqrt{\mathrm{r}}$, where $\mathrm{r}$ is the distance from the source. On the basis of theoretical considerations, it has been shown that $67 \%$ of the energy is contained in the Rayleigh wave, $26 \%$ in the shear wave, and only $7 \%$ in the compression wave. This, and the fact that the Rayleigh wave decays more slowly, leads one to conclude, as stated by Richart et al. [1], that "...the Rayleigh wave is of primary concern for foundations on or near the surface of the earth."

The particle motion associated with the Rayleigh wave is made up of two components (one vertical, the other horizontal), the amplitudes of which vary with depth. The source identification technique under consideration uses the horizontal component of this wave. In a straightforward manner, as illustrated in Fig. 2, the RMS amplitudes of two orthogonal components of the horizontal displacement vector are measured with a pair of accelerometers. These amplitudes are used to compute the absolute value of the vector angle with respect to a reference datum, in this study a reference line pointing north. This defines two directional lines, one of which will correspond to a radial line emanating from the vibration source. By positioning the accelerometer pairs at $\mathrm{n}$ different locations, $2 \mathrm{n}$ dimensional lines are generated. Theoretically, the intersection of $\mathrm{n}$ of these lines defines the source location; see the illustration in Fig. 3. Practically, some engineering judgment will be required. In this regard, additional information, such as the location of buildings and of the equipment within the buildings, will be helpful.

\section{Implementation}

Triaxial accelerometers (PCB Model 393C) were mounted on 2-ft-long stakes driven into the soil surface and were used to measure the ground motion at various selected locations near Building 335. The two horizontal accelerometers were oriented so that one of them sensed motion in a northerly direction and the other in an easterly direction. The locations where ground motion was measured 
are indicated on Fig. 4, and identified by numbers 1-15. The resulting acceleration-time signals were double-integrated to obtain displacements, and power spectral densities of the displacement-time signals were calculated with a HP Model 354 Spectrum Analyzer. For each spectral frequency of interest, the absolute value of the vector angle defining the directional lines (with respect to North) was calculated as

$$
\mid \text { angle } \mid=\arctan \left[\frac{\text { RMS disp }- \text { east }}{\text { RMS disp - north }}\right] .
$$

Often, as in this study, a probable source (in this case, Building 335) can be identified, and the directional lines pointing to it are those used for the location process.

\section{Results}

Ground motion was measured at the various locations shown in Fig. 4 throughout the day (not simultaneously) at two specific times, i.e., when the large-amplitude $8-\mathrm{Hz}$ signal was present, and when it was off. Typical power spectra with and without the 8- $\mathrm{Hz}$ signal are shown in Figs. 5 and 6, respectively. Total RMS displacements, calculated from the power spectral density plots, are tabulated in Table 1. To normalize the measurements, a reference triaxial accelerometer, which remained stationary for all tests, was located at Position 2, shown in Fig. 4.

\section{\&-Hz Ground Motion}

Digital filtering techniques were used on power spectral density data, such as that given in the plots of Figs. 5 and 6 , to obtain the displacement contribution from the $8-\mathrm{Hz}$-frequency component. The results are summarized in Table 2. One accelerometer triplet was moved to the various locations and the vertical, horizontal-north, and horizontal-east measurements were made at each location. The vector angle of the directional line indicating the location of the source is calculated from the horizontal displacements with the $8-\mathrm{Hz}$ source active. Depending on location, this angle varied from 13.6 to 75 degrees.

Another accelerometer triplet remained at Location 2 throughout all the measurements and is referred to as "Reference Position, Location 2." The vector angle associated with the reference triaxial accelerometer, referred to as "Ref. Position (Deg)" was calculated in like manner. If the location of the excitation source remained constant with time, this angle should have also remained 
constant. Using "some imagination" and with a few exceptions, this was generally the case, as shown in Table 2.

In Fig. 7, the source directional lines are shown in relation to the plan view of Building 335. For most locations, we plotted only the more probable directional line,as determined by speculating that the excitation source was located in Building 335. All directional lines, with the exception of those from Locations 5 and 6 , indicate that the building is the source of the excitaticn. The failure of Locations 5 and 6 to point to the building as the source of excitation may be due to the low amplitude level of the $8-\mathrm{Hz}$ signal at these locations relative to both ambient ground motion and electrically-generated noise in the measurement instrumentation. In all cases, when the $8-\mathrm{Hz}$ source was on, the vertical amplitude was significantly larger than the horizontal amplitudes; a possible indication of the direction of the force at the location of the excitation source.

Although the modal response of the building floor was not considered, there appear to be three groups of intersecting lines in Fig. 7, each of which may be an indicator of a vibration source. One group consists of intersecting lines from Locations 3, 4, and 7. Another group consists of intersecting lines from Locations 2 , possibly 7 , and 11 . The third group consists of intersecting lines from Locations $2,8,9,10$, and 15 . The latter group intersects in the approximate location of the building air compressor.

The source of the $8-\mathrm{Hz}$ ground excitation was determined to be a Worthington vertical-cylinder air compressor powered by a $7.5-\mathrm{hp}, 1740-\mathrm{pm}$ electric motor. The compressor rotates at $\approx 478 \mathrm{rpm}$, with a duty cycle corresponding to that observed in Fig. 1. The compressor assembly was mounted on a large (38.5 in. $\times 105$ in. $\times$ unknown depth) concrete block that appeared to be vibration-isolated from the rest of the floor. It appears that $8 \mathrm{~Hz}$ is also a vertical resonant frequency of the building floor and that the compressor and floor are acting as a coupled system.

\section{0-Hz Ground Motion}

A reasonably large, $\approx 30-\mathrm{Hz}$ ground motion response was observed at Locations 4, 5, and 7; however, it appeared to be unrelated to the compressor duty cycle. Typical power spectra from Localion 4, with and without the compressor operating, are shown in Figs. 8 and 9, respectively. As with the $8-\mathrm{Hz}$ excitation, the sharpness of the response indicates that it may be a mechanical system operating at a constant speed of $\approx 1800 \mathrm{rpm}$, such as an air-handling fan or direct coupled refrigeration compressor. RMS displacements and associated vector angles defining the directional lines are tabulated in Table 3 . In this case, the largest amplitude observed is in the horizontal direction, which may be an 
indication of the direction of the excitation force. The plot of the directional lines, Fig. 10, indicates the source may also be in Building 335. Because the excitation was observed for a limited time and only at three locations, and because of time constraints, no attempt was made to identify the actual source.

\section{3-38-Hz Ground Motion}

On several power spectrum density plots, a large horizontal-displacement response, not related to the duty cycle of the compressor, was observed at a frequency of 33-38 Hz; response components can be observed on the plots given in Figs. 5 and 6 . The band of frequencies remained fairly constant for the reference triaxial accelerometer, but varied considerably for the "portable" triaxial accelerometer. The directional lines, which were defined from the vector angle determined as the average of the measured angles (Locations 2-15 averaged), are shown in Fig 11. Again, although the directional lines appear to indicate a source within Building 335 , in all probability, this response is a resonance of the accelerometer triaxial/stake/ground system responding to ambient ground motion and is not an isolated excitation source within the building. The variable nature of the frequency response can be accounted for by the fact that the reference accelerometer triplet remained at one location whereas the other was moved to various locations. This illustrates the need for exercising care and engineering judgment when measuring ground motion, and especially when interpreting the reduced data.

\section{1-Hz Ground Excitation}

A large $41-\mathrm{Hz}$ displacement amplitude was observed in the power spectra from Location 8 (see Fig. 12); a much smaller amplitude was observed at Location 9. The $41-\mathrm{Hz}$ ground vibration could not be correlated to the duty cycle of the compressor, nor could it be determined if the response was time-related. The measured RMS displacements, Table 4, show that most of the displacement is in the horizontal direction. The directional line (Fig. 13) indicates that a probable source is within Building 335. Again, because of time constraints, no attempt was made to identify the source.

\section{Summary/Conclusions}

The results of this study demonstrate that a triangulation scheme, based on orthogonal, horizontal RMS displacements, represents a potentially useful tool in identifying the location of an excitation source. A complementary technique, which was not evaluated in this study, would be to place a string of transducers 
along a measured directional line and observe the increase/decrease of amplitude as a function of distance.

A limitation of the technique evaluated here is that the source must be continuous for a sufficient period of time to generate an accurate power spectral density representation. This is necessary to calculate the RMS displacement contributions. In reality, this may not be much of a limitation, because continuous ground vibration sources will be the sources of concern, rather than transient excitations, which would have a small effect on the stability of the APS storage ring beam.

A knowledge of site dynamics, such as dynamic characteristics of buildings and large mechanical systems, and of operating schedules, will be necessary to facilitate the implementation of the source detection scheme described in this report.

\section{References}

1. Richart, F. E., Jr., Hall, J. R., and Woods, R. D., Vibrations of Soils and Foundations, Prentice-Hall, Inc., NJ (1970).

\section{DISCLAIMER}

\footnotetext{
This report was prepared as an account of work sponsored by an agericy of the United States Government. Neither the United States Government nor any agency thereof, nor any of their employees, makes any warranty, express or implied, or assumes any legal liability or responsibility for the accuracy, completeness, or usefulness of any information, apparatus, product, or precess dis:losed, or represents that its use would not infringe privately owned rights. Reference herein to any specific commercial product, process, or service by trade name, trademark, manufacturer, or otherwise does not necessarily constitute or imply its endorsement, recommendation, or favoring by the United States Government or any agency thereof. The views and opinions of authors expressed herein do not necessarily state or reflect those of the United States Government or any agency thereof.
} 
Table 1. Wideband (4-100 Hz) RMS ground displacement $\left(10^{-9} \mathrm{~m}\right)$ at various locations

\begin{tabular}{|c|c|c|c|}
\hline Locationa & Vertlcal & Horiz. North & Horlz. East \\
\hline 1,0 & 40.7 & 2.37 & 74.63 \\
\hline $1, x$ & 109 & 2.3 & 98.4 \\
\hline 2,0 & 43 & 95.9 & 108 \\
\hline $2, x$ & 80.2 & 113 & 106 \\
\hline 3,0 & 43.2 & 72.5 & 72.9 \\
\hline $3, x$ & 75.3 & 68.7 & 64.4 \\
\hline 4,0 & 40.9 & 103 & 79.1 \\
\hline $4, x$ & 68.9 & 109 & 91.5 \\
\hline 5.0 & 38.8 & 167 & 79.4 \\
\hline $5, x$ & 61.8 & 307 & 78.6 \\
\hline 6,0 & 40.9 & 54.8 & 55.4 \\
\hline $6, x$ & 66.1 & 54.4 & 54.5 \\
\hline 7,0 & 59.7 & 74.9 & 74 \\
\hline $7, x$ & 87.6 & 85.5 & 83.3 \\
\hline 8,0 & 76.6 & 106 & 106 \\
\hline $8, x$ & 91.6 & 79.9 & 78.1 \\
\hline 9.0 & 51.5 & 107 & 98.4 \\
\hline $9, x$ & 112 & 130 & 115 \\
\hline 10.0 & 46.1 & 128 & 136 \\
\hline $10, x$ & 118 & 94.6 & 150 \\
\hline 11,0 & 67.1 & 207 & 226 \\
\hline $11, x$ & 112 & 157 & 220 \\
\hline 12,0 & 46.8 & 197 & 260 \\
\hline $12, x$ & 83.8 & 187 & 231 \\
\hline 13,0 & 51.6 & 121 & 89 \\
\hline $13, x$ & 146 & 184 & 101 \\
\hline 14,0 & 50.1 & 103 & 139 \\
\hline $14, x$ & 52.5 & 87.5 & 98.4 \\
\hline 15,0 & 58.9 & 172 & 109 \\
\hline $15, x$ & 427 & 301 & 213 \\
\hline
\end{tabular}

$a_{0}-$ No $8-H z$ ground motion; $x-8-H z$ ground motion 
Table 2. 8-Hz component of measured ground displacement and associated vector angles

\begin{tabular}{|c|c|c|c|c|c|c|c|c|}
\hline \multirow[b]{3}{*}{$\begin{array}{l}\text { Loca- } \\
\text { tiona }\end{array}$} & \multirow[b]{3}{*}{$\begin{array}{c}\text { Vertl- } \\
\text { cal }\end{array}$} & \multirow{3}{*}{$\begin{array}{c}\text { RMS } \\
\text { Horiz. } \\
\text { North }\end{array}$} & \multicolumn{4}{|c|}{ Displacement $\left(10^{-9} \mathrm{~m}\right)$} & \multirow{3}{*}{ Vector } & \multirow{3}{*}{$\begin{array}{l}\text { Angle } \\
\text { Ref. } \\
\text { Position } \\
\text { (Degb) }\end{array}$} \\
\hline & & & \multirow[b]{2}{*}{$\begin{array}{c}\text { Horlz. } \\
\text { East }\end{array}$} & \multicolumn{3}{|c|}{$\begin{array}{c}\text { Reference Position, } \\
\text { Location } 2 \\
\end{array}$} & & \\
\hline & & & & $\begin{array}{c}\text { Verti- } \\
\text { cal }\end{array}$ & $\begin{array}{l}\text { Horlz. } \\
\text { North }\end{array}$ & $\begin{array}{c}\text { Horiz. } \\
\text { East }\end{array}$ & & \\
\hline 2,0 & 11.1 & 17.5 & 19.6 & 10.7 & 9.96 & 12.9 & & \\
\hline $2, x$ & 65.5 & 44.4 & 23.3 & 106 & 47.7 & 21.5 & 27.7 & 24.3 \\
\hline 3,0 & 15.19 & 18 & 1902 & 14.2 & 16.4 & 26.2 & & \\
\hline $3, x$ & 61.9 & 21.5 & 18.5 & 69.8 & 34.8 & 23.5 & 40.7 & 34.0 \\
\hline 4,0 & 11.6 & 14.8 & 12.4 & 11 & 9.83 & 13.1 & & \\
\hline $4, x$ & 54.4 & 27.8 & 15.3 & 70.3 & 32.7 & 17.9 & 28.8 & 28.7 \\
\hline 5,0 & 10.5 & 34.2 & 15.1 & 11.7 & 8.84 & 13.1 & & \\
\hline $5, x$ & 46.7 & 77.3 & 19.4 & 69.8 & 33.1 & 17.1 & 14.1 & 27.3 \\
\hline 6,0 & 9.94 & 11 & 12.5 & 9.95 & 17.1 & 20.6 & & \\
\hline $6, x$ & 49.7 & 18.2 & 13.9 & 70.3 & 34.7 & 18.5 & 37.4 & 28.1 \\
\hline 7,0 & 21.2 & 20.1 & 20.3 & 18.2 & 13.2 & 20.9 & & \\
\hline $7, x$ & 74.5 & 26.7 & 30 & 70.2 & 37.1 & 27.1 & 48.3 & 36.1 \\
\hline 8,0 & 53.4 & 20 & 22.7 & 50.9 & 27.5 & 27.9 & & \\
\hline $8, x$ & 75.7 & 25.4 & 26.6 & 69.2 & 31.1 & 28.5 & 46.3 & 42.5 \\
\hline 9,0 & 10.3 & 16 & 20.8 & 12.3 & 13.2 & 23.5 & & \\
\hline $9, x$ & 99.3 & 47.8 & 39.8 & 71.5 & 31 & 20.1 & 39.86 & 33.0 \\
\hline 10,0 & 13.3 & 18.6 & 20.5 & 9.83 & 13.2 & 15.6 & & \\
\hline $10, x$ & 108 & 23.8 & 92.9 & 68.8 & 33.9 & 16.1 & 75.6 & 25.4 \\
\hline 11,0 & 21.4 & 36.8 & 30.9 & 23.5 & 21.5 & 30.5 & & \\
\hline $11, x$ & 103 & 20.5 & 41.2 & 69.6 & 33.6 & 19.5 & 63.5 & 30.1 \\
\hline 12,0 & 15.4 & 22.4 & 35 & 14.4 & 10.3 & 35 & & \\
\hline $12, x$ & 69.3 & 29.5 & 62.6 & 66.1 & 27.9 & 36.1 & 64.8 & 52.3 \\
\hline 13,0 & 21.1 & 24.4 & 48.1 & 23.2 & 10.3 & 43.7 & & \\
\hline $13, x$ & 135 & 113 & 44 & 72.3 & 35.1 & 31.7 & 21.3 & 42.1 \\
\hline 14,0 & 15.3 & 17.1 & 46.2 & 12.3 & 9.76 & 29.1 & & \\
\hline $14, x$ & 13.1 & 22.3 & 52.4 & 11.5 & 9.5 & 31.4 & 67.0 & 73.2 \\
\hline 15,0 & 13.5 & 23 & 39.7 & 17.1 & 18.7 & 40.1 & & \\
\hline $15, x$ & 406 & 178 & 43 & 80.9 & 31.9 & 39.5 & 13.6 & 51.1 \\
\hline
\end{tabular}

$a_{0}-$ No $8-\mathrm{Hz}$ ground motion; $x-8 \cdot \mathrm{Hz}$ ground motion

bDeg - Degrees from north 
Table 3. 30-Hz component of measured ground displacement and associated vector angle

\begin{tabular}{|c|c|c|c|c|}
\hline \multirow[b]{2}{*}{ Locationa } & RMS & Displacement & $\left(10^{-9} \mathrm{~m}\right)$ & \multirow[b]{2}{*}{$\begin{array}{l}\text { Angle } \\
\left(D e g^{b}\right)\end{array}$} \\
\hline & Vertical & $\begin{array}{l}\text { Horiz. } \\
\text { North }\end{array}$ & $\begin{array}{c}\text { Horiz. } \\
\text { East }\end{array}$ & \\
\hline 4,0 & 3.9 & 68.6 & 49.3 & 35.7 \\
\hline $4, x$ & 4.21 & 76.7 & 58.1 & 37.1 \\
\hline 5,0 & 3.26 & 23.3 & 26 & 48.1 \\
\hline $5, x$ & 3.15 & 22.1 & 22.1 & 45.0 \\
\hline 7,0 & 1.72 & 12.4 & 16.9 & 53.7 \\
\hline $7, x$ & 1.68 & 12 & 16.4 & 53.8 \\
\hline
\end{tabular}

$a_{0}-$ No $8-\mathrm{Hz}$ ground motion; $\mathrm{x}-8 \mathrm{-Hz}$ ground motion bDeg - Degrees from north

Table 4. 41- $\mathrm{Hz}$ component of measured ground displacement and associated angle

\begin{tabular}{ccccc}
\hline & \multicolumn{2}{c}{ RMS Displacement } & $\left(10^{-9} \mathrm{~m}\right)$ & Vector \\
\cline { 2 - 4 } Locationa & Vertical & $\begin{array}{c}\text { Horiz. } \\
\text { North }\end{array}$ & $\begin{array}{c}\text { Horlz. } \\
\text { East }\end{array}$ & $\begin{array}{c}\text { Angle } \\
(\text { Deg })\end{array}$ \\
\hline 8,0 & 7.82 & 69.5 & 64.6 & 42.9 \\
\hline
\end{tabular}

$a_{0}$ - No $8-\mathrm{Hz}$ ground motion; $\mathrm{x}-8 \mathrm{-Hz}$ ground motion bDeg - Degrees from north 


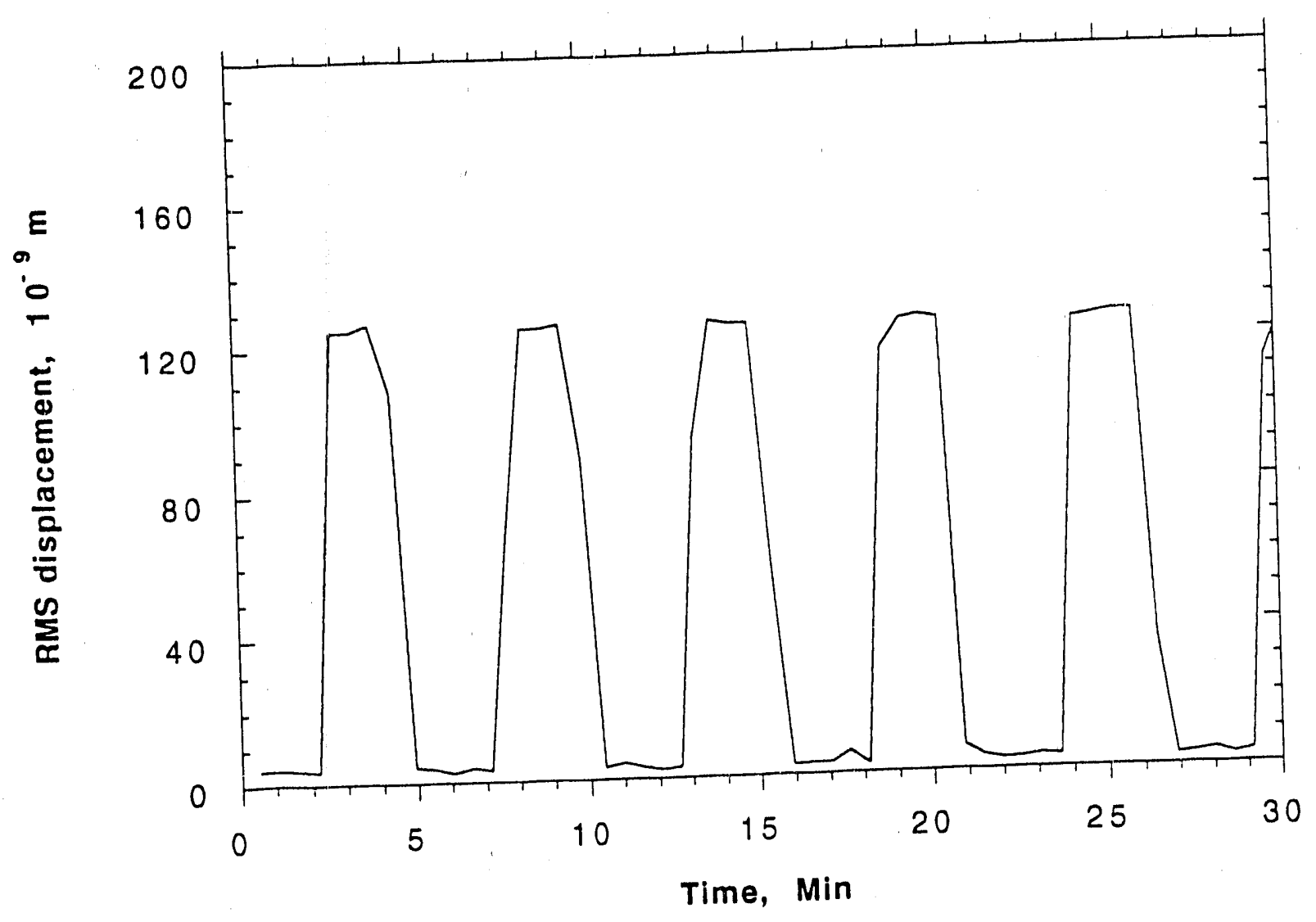

Fig. 1. 8- Hz component of vertical floor displacement in Bldg. 335 


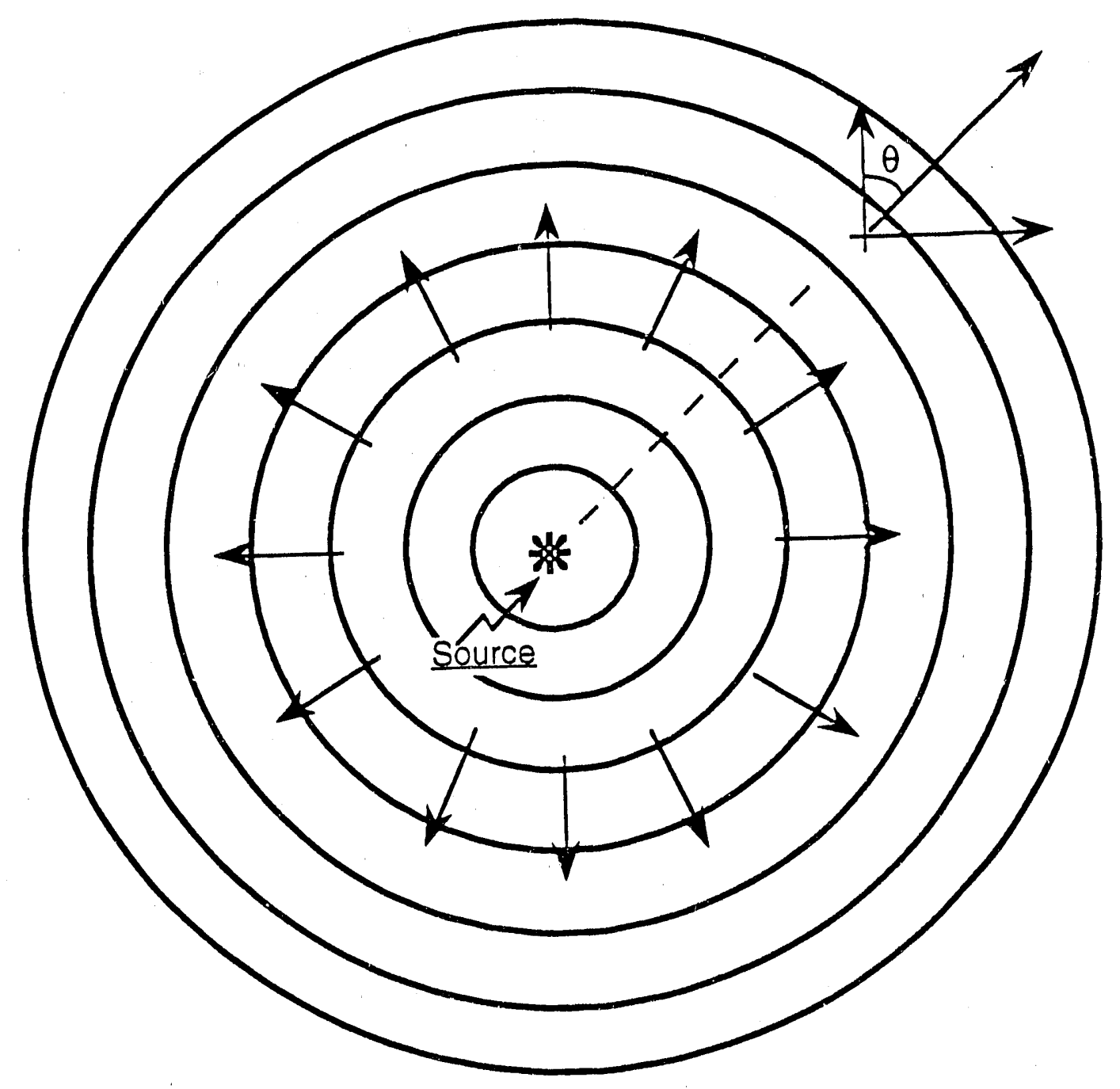

Fig. 2. Wave propagation from excitation source 


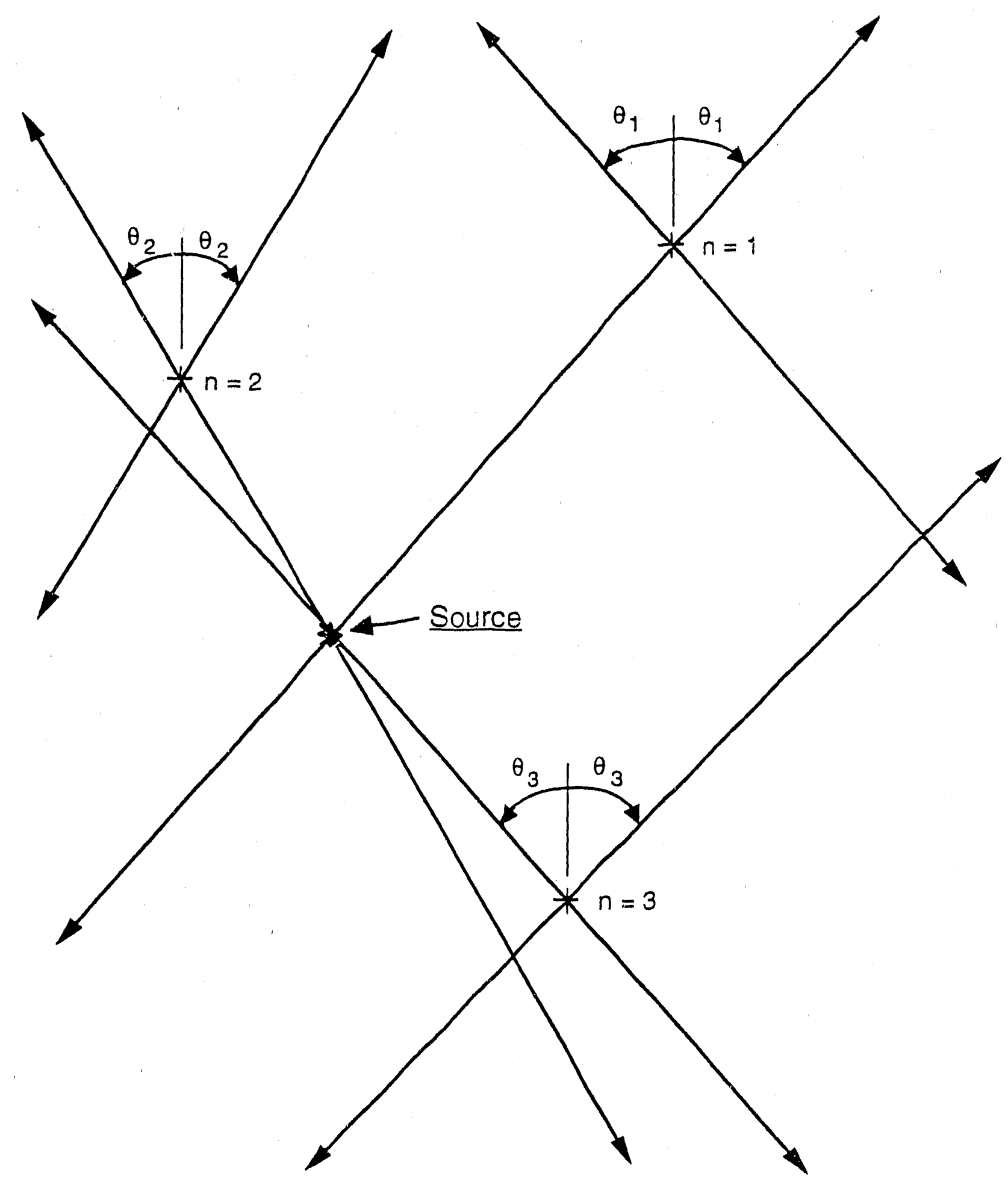

Fig. 3. Source identification scheme with three accelerometer pairs $(n=3)$ in horizontal orientation 
$t_{12}$
${ }_{14}^{+}$
$+13$

4

North

$T_{8}$
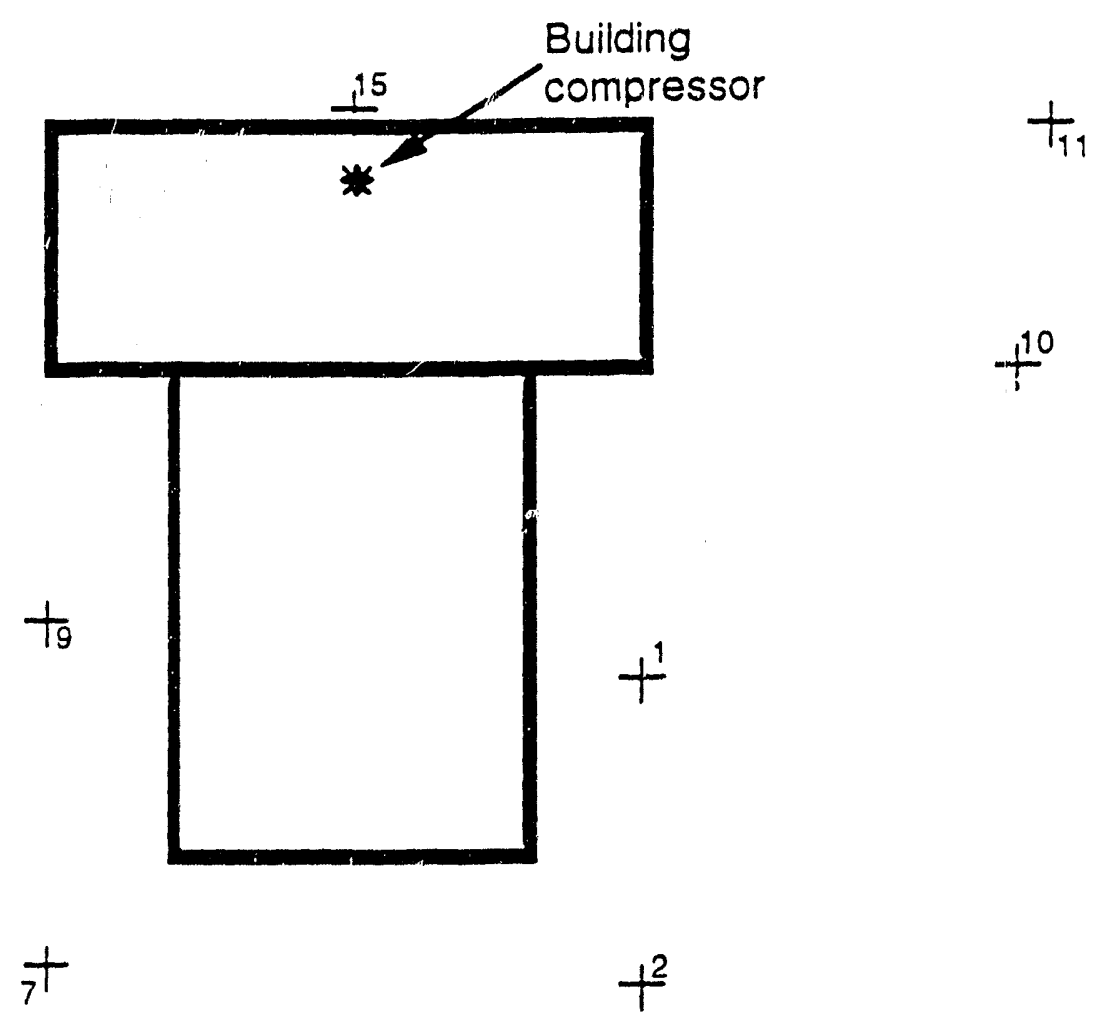

$+10$

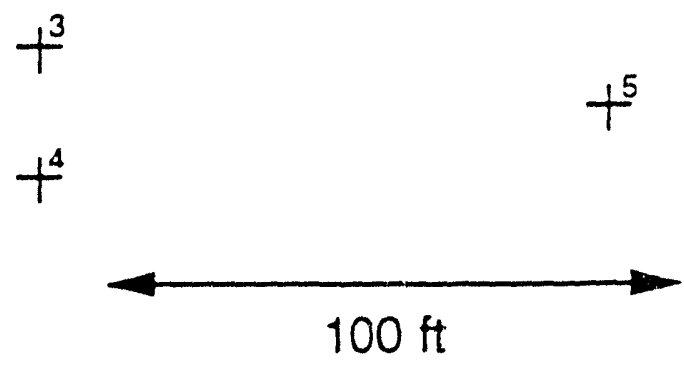

Fig. 4. Locations where ground motion was measured 

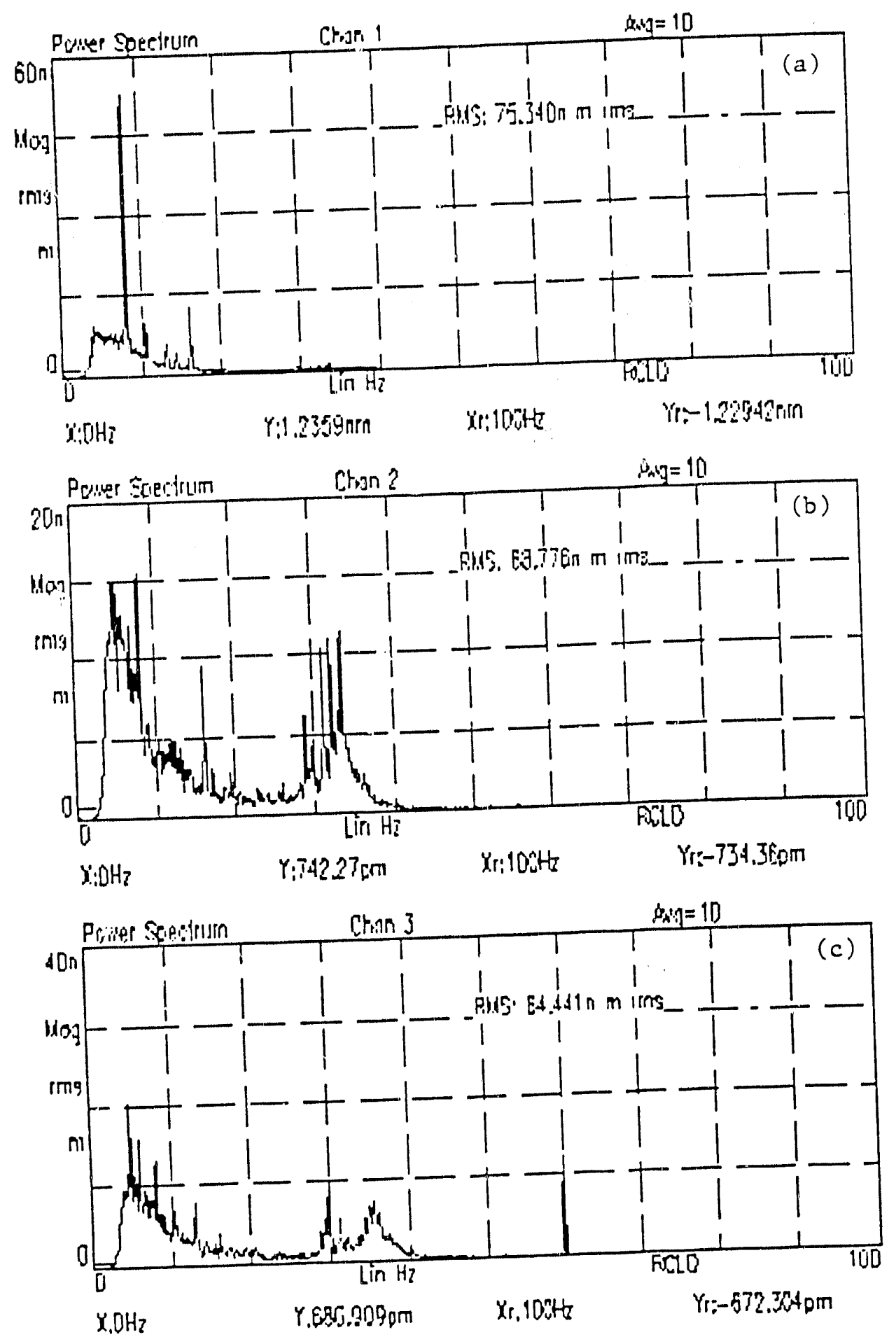

Fig. 5. Ground motion response spectra at Location 3 ( $8-\mathrm{Hz}$ excitation present): (a) vertical response; (b) horizontal response, north; (c) horizontal response, east 

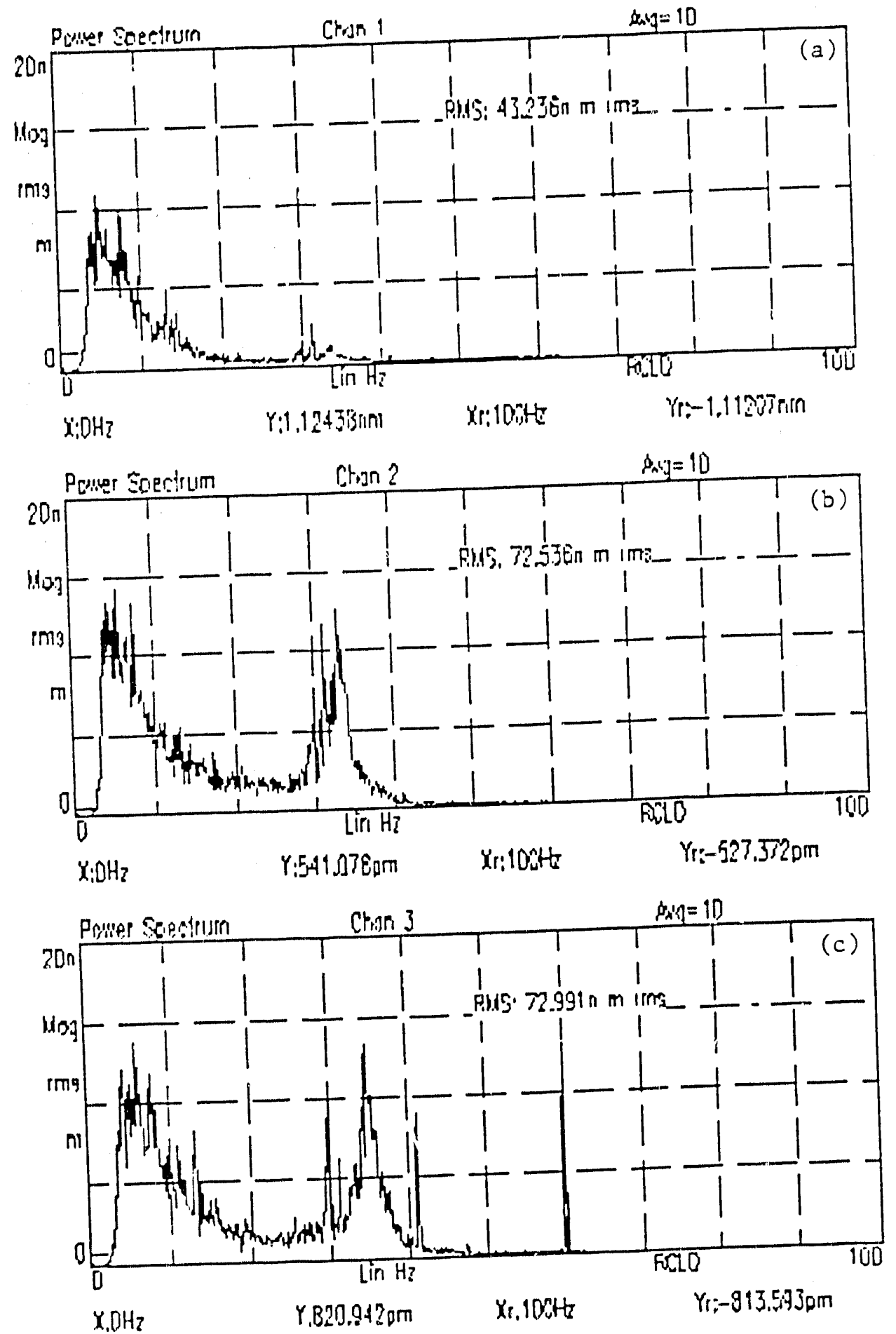

Fig. 6. Ground motion response spectra at Location 3 (8- $\mathrm{Hz}$ excitation off): (a) vertical response; (b) horizontal response, north; (c) horizontal response, east 


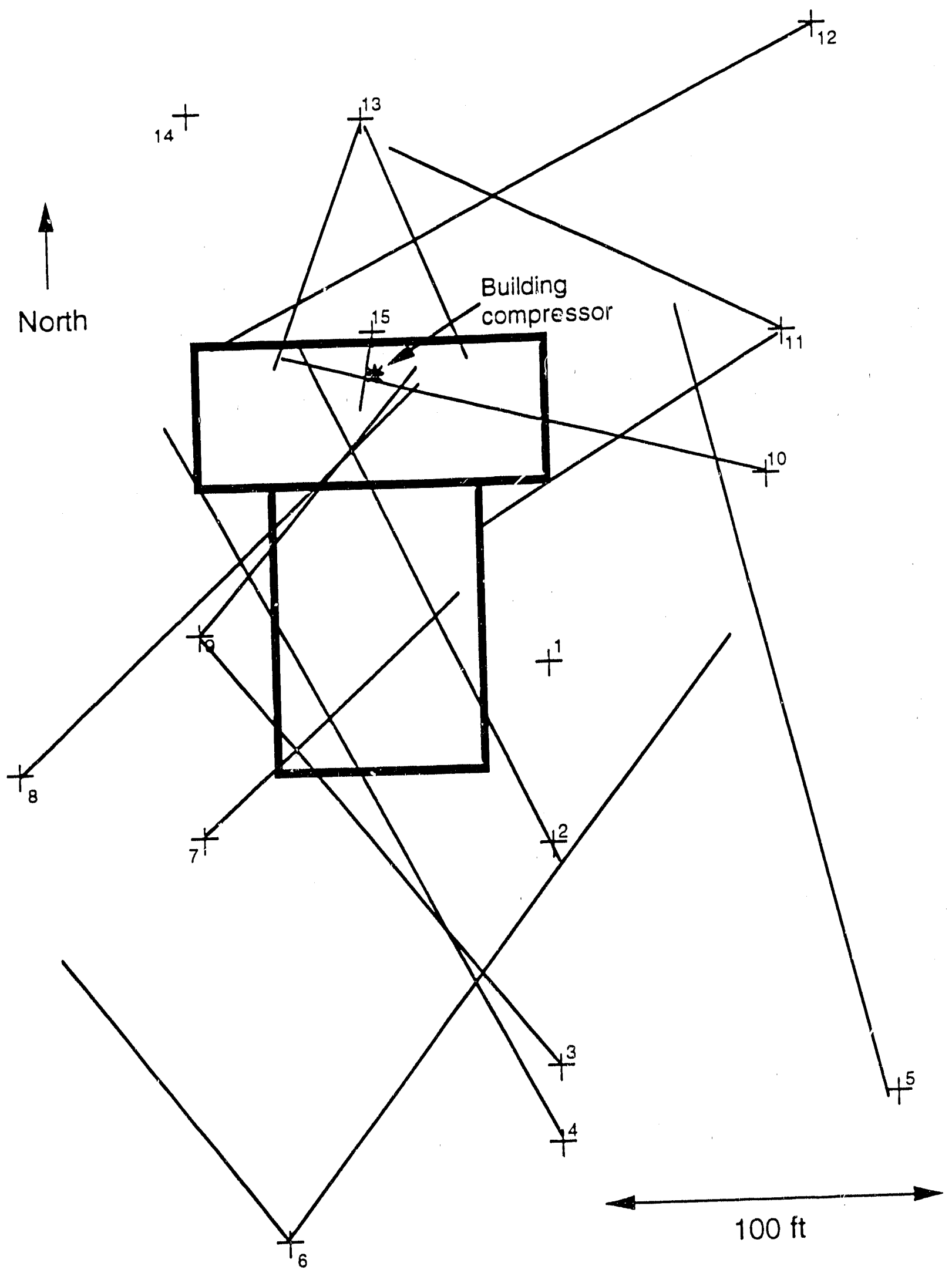

Fig. 7. Directional lines defined from $8-\mathrm{Hz}$ component of ground motion 

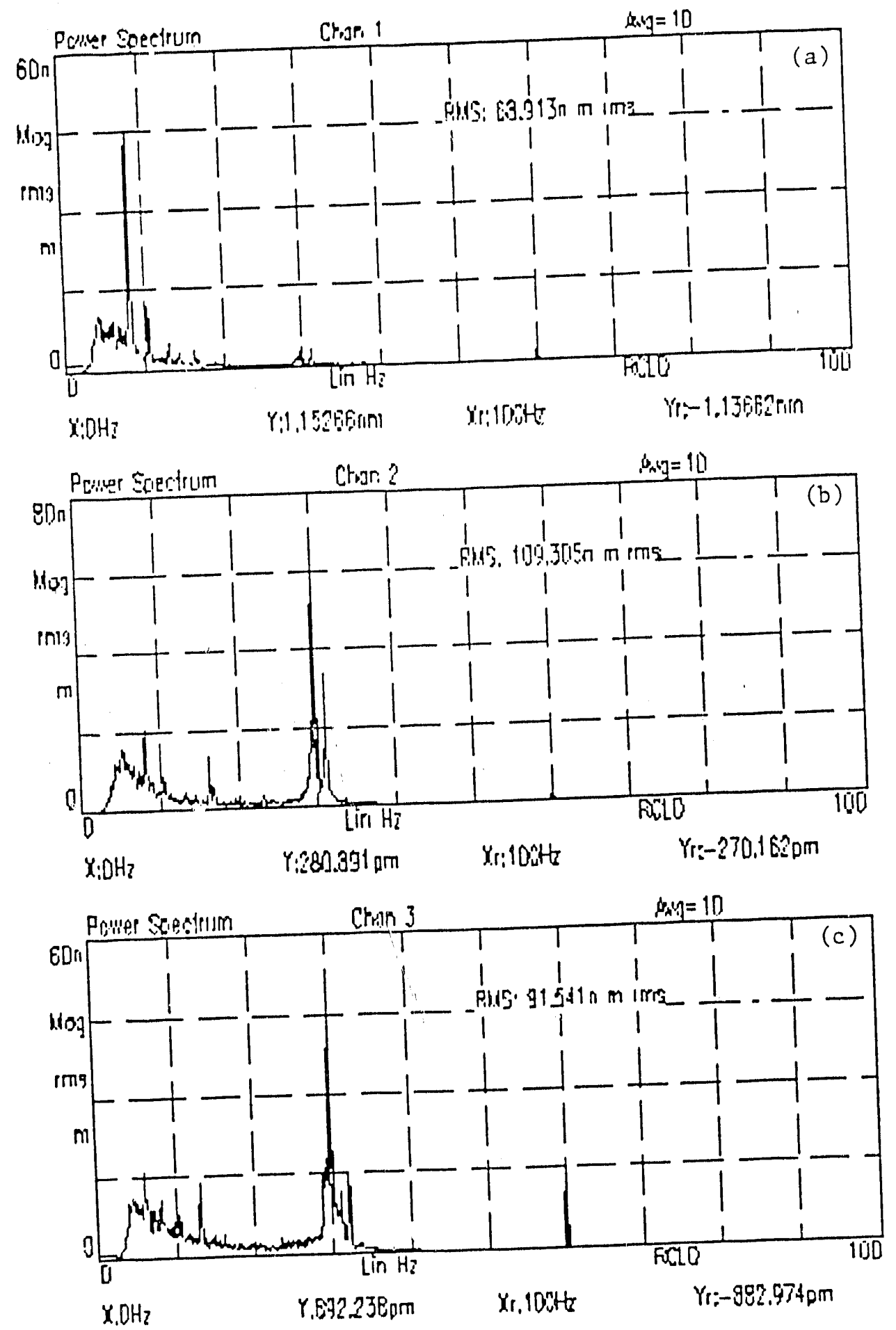

Fig. 8. Ground motion response spectra at Location 4, showing $30-\mathrm{Hz}$ component (8-Hz excitation on): (a) vertical response; (b) horizontal response, north; (c) horizontal response, east 

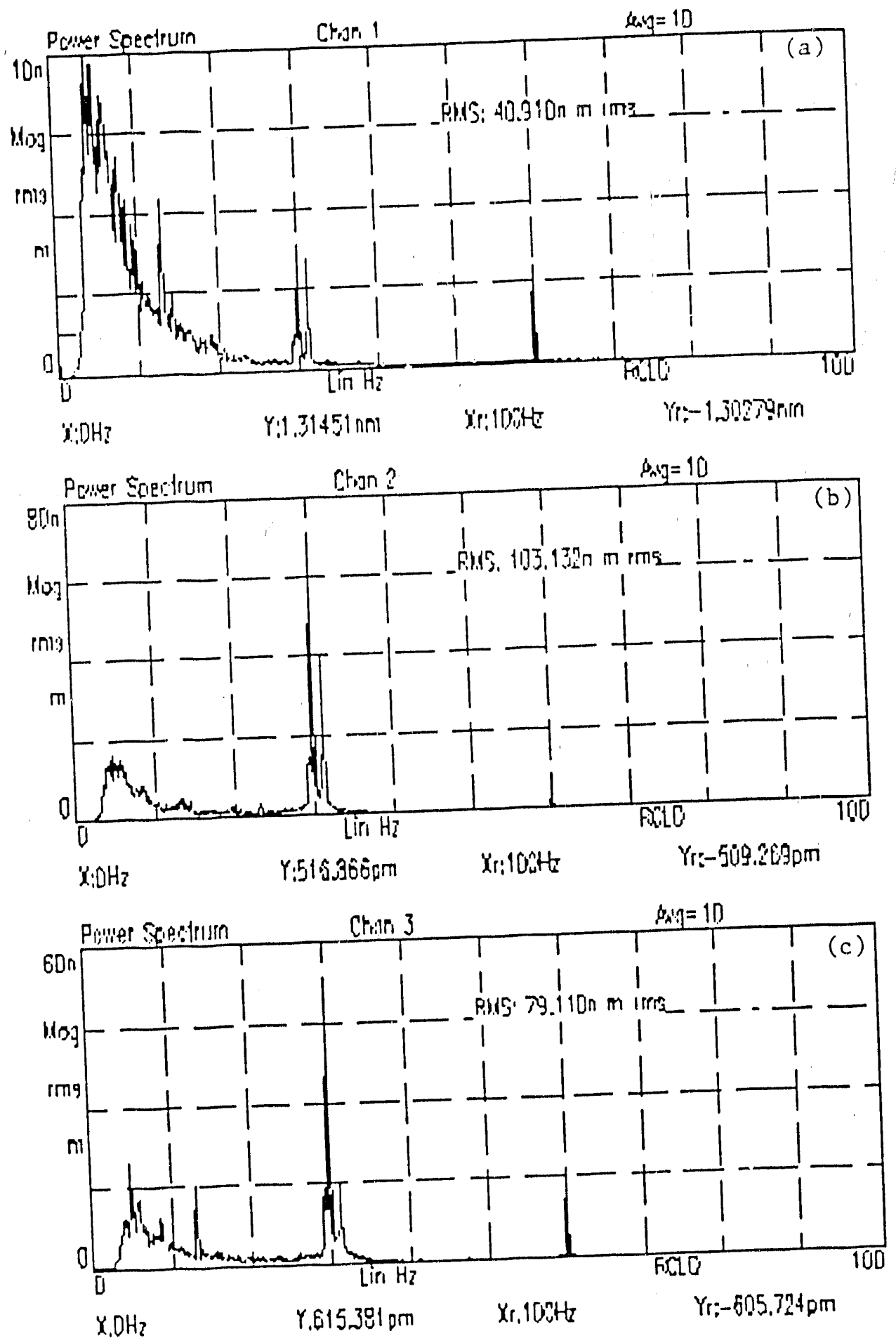

Fig. 9. Ground motion response spectra at Location 4, showing $30-\mathrm{Hz}$ component (8- $\mathrm{Hz}$ excitation off): (a) vertical response; (b) horizontal response, north;

(c) horizontal response, east 

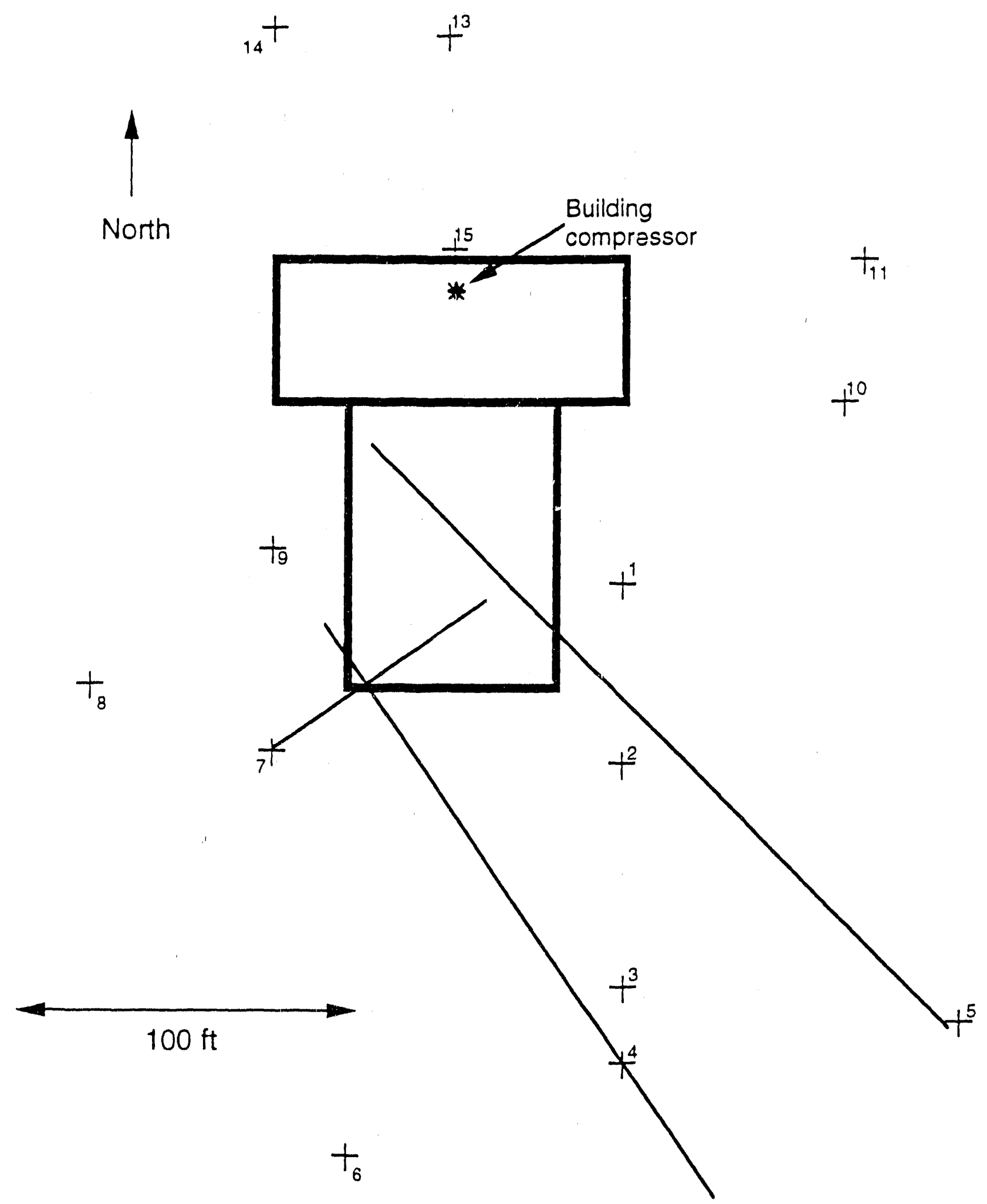

Fig. 10. Directional lines defined from $30-\mathrm{Hz}$ component of ground motion 
$+t^{13}$

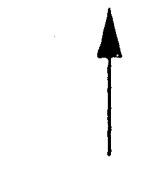

North
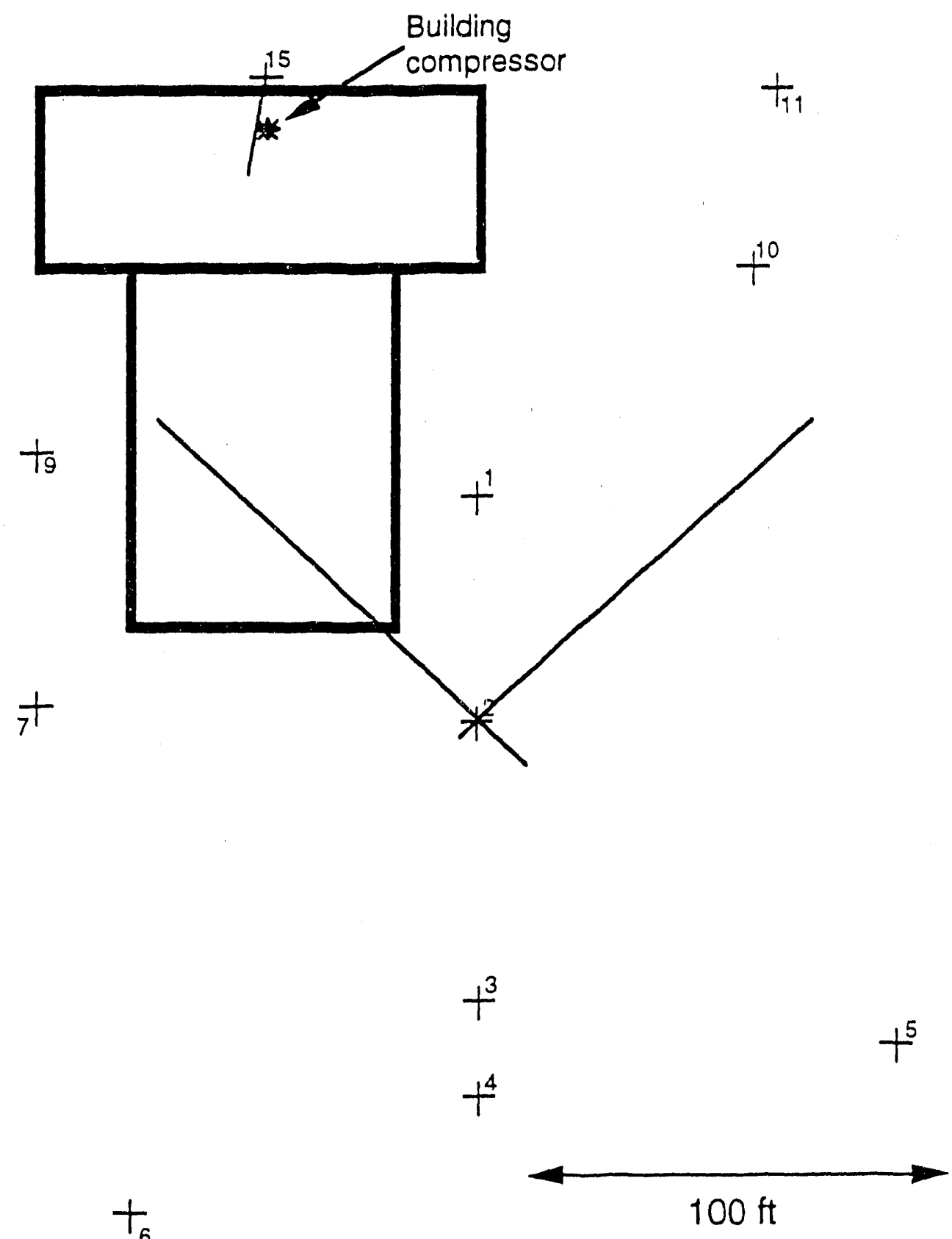

Fig. 11. Directional lines defined from 33-38-Hz component of ground motion 

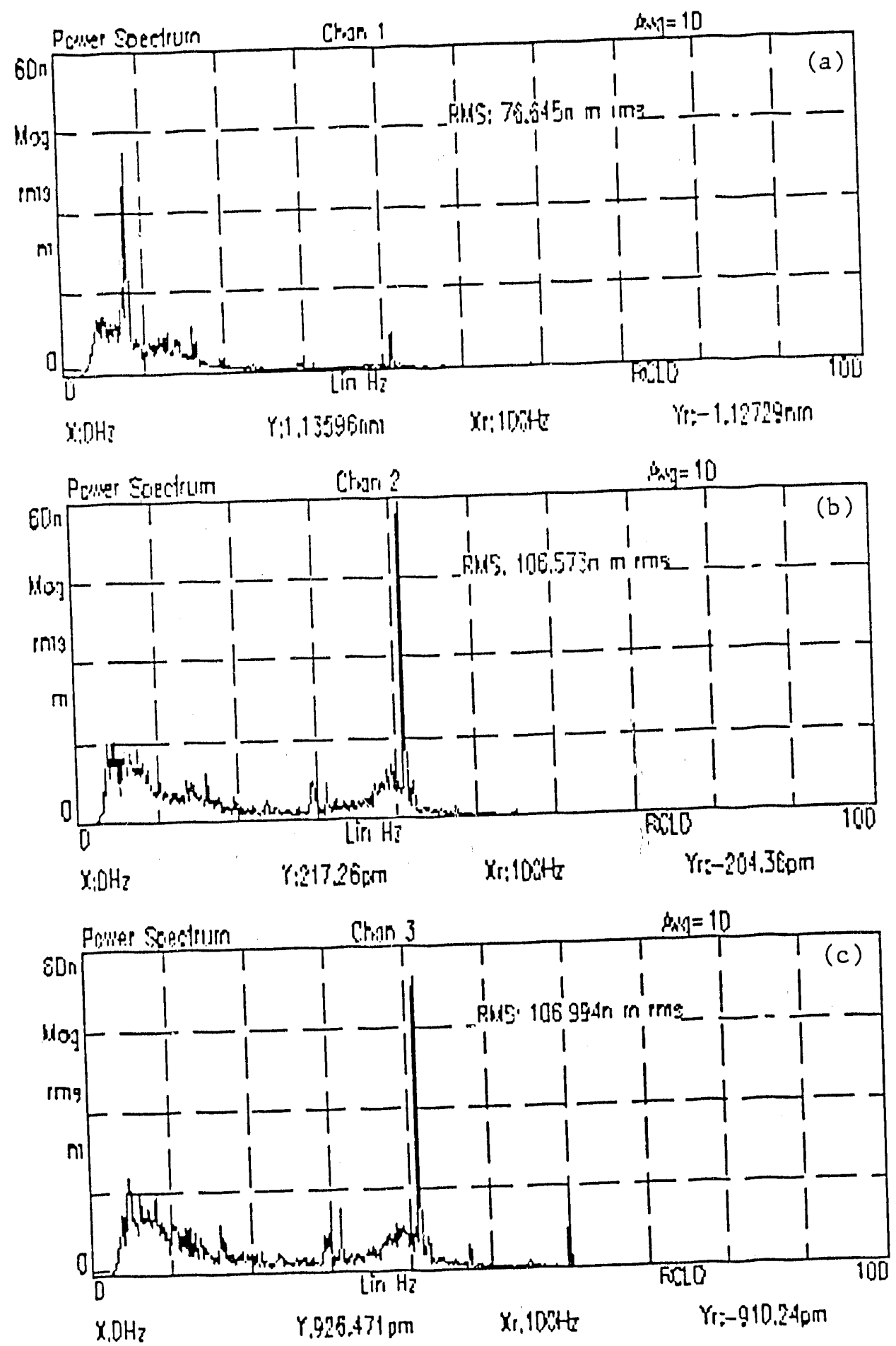

Fig. 12. Ground motion response spectra at Location 8 , showing $41-\mathrm{Hz}$ component: (a) vertical response; (b) horizontal response, north; (c) horizontal response, east 


$$
+14
$$

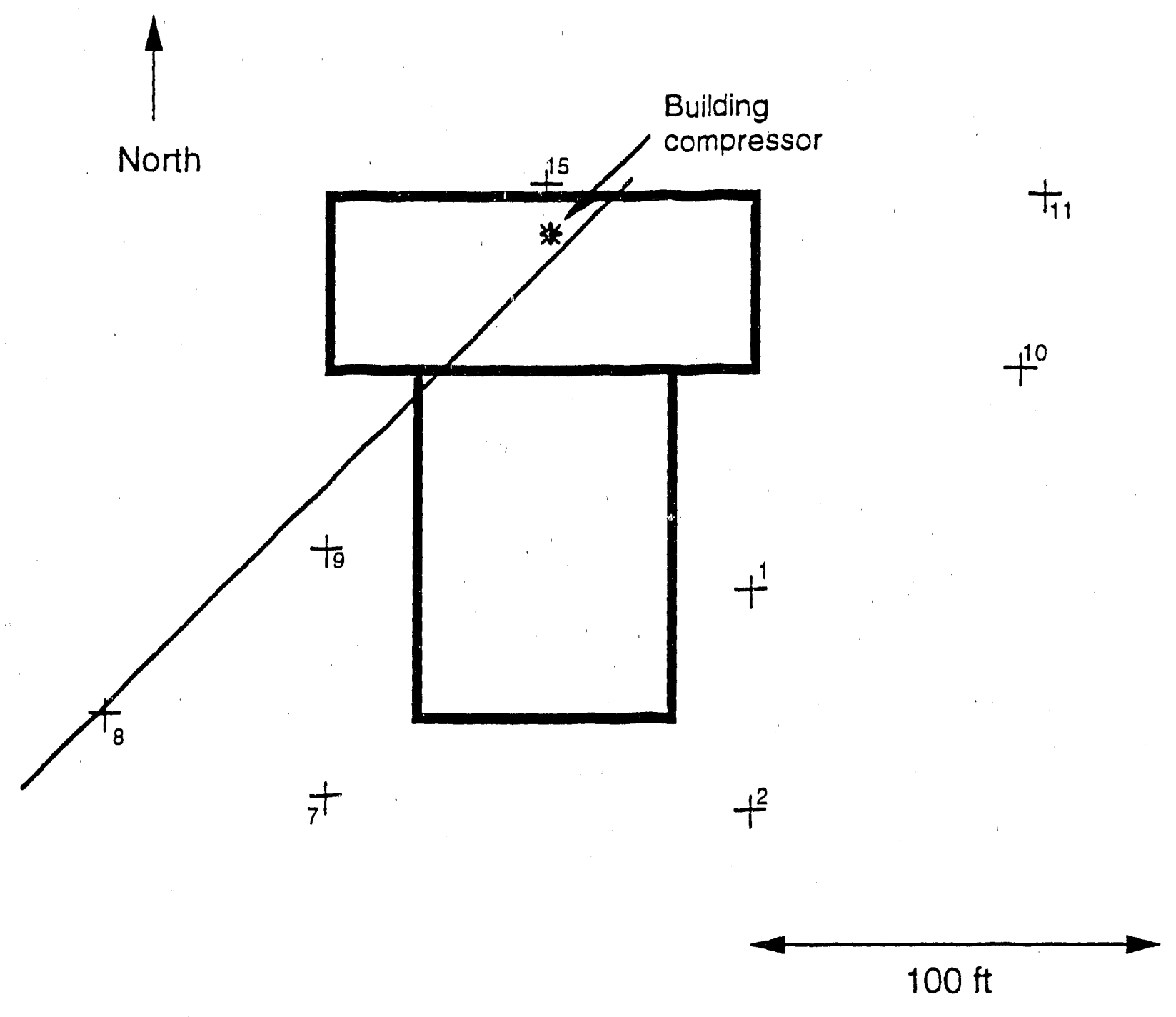

Fig. 13. Directional lines defined from $41-\mathrm{Hz}$ component of ground motion 

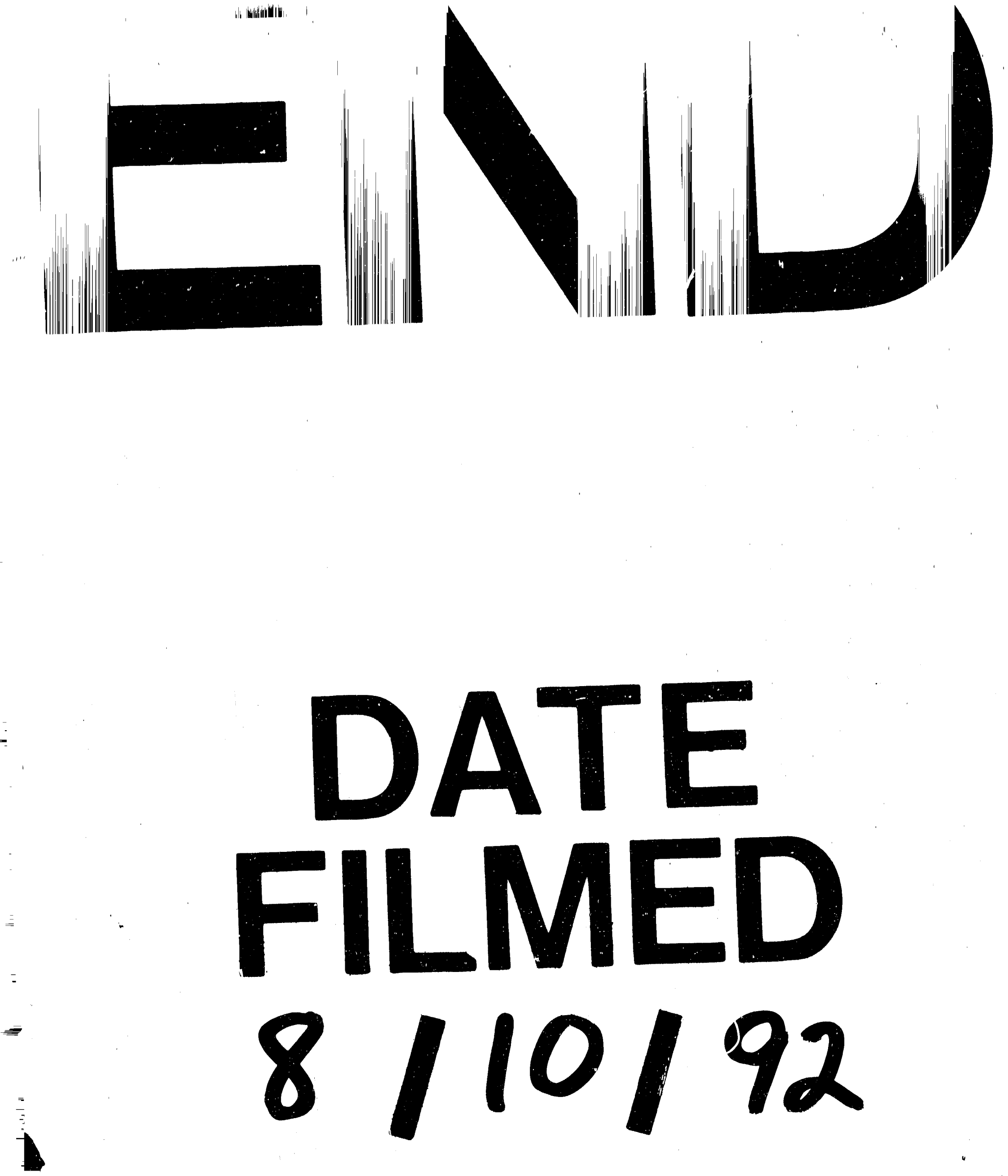

- 
$=$

$=$

$=$
$=$ 